\title{
If New York Is Not in the United States, It's in California
}

ABSTRACT: An argument is presented for the truth of the conditional, 'If New York is not in the United States, it's in California'. Several possible objections to this argument are then examined and evaluated. Further argument establishes that if the argument for the truth of 'If New York is not in the United States, it's in California' is sound, it follows that an indicative conditional is true if and only if it has either a false antecedent or a true consequent.

KEYWORDS: indicative conditional, truth-conditions, false antecedent, true consequent

\section{I.}

Let us call an indicative conditional a Philonian conditional if it has either a false antecedent or a true consequent. (Hereinafter, 'conditional' will mean 'indicative conditional'.) And let us give the name 'the Philonian thesis' to the thesis that a conditional is true if and only if it is a Philonian conditional. ${ }^{\mathrm{I}}$ Many philosophers (perhaps even a substantial majority of the philosophers who have taken a stand on the matter) maintain that the Philonian thesis is false. One among several reasons the Anti-Philonians (so I will call them) urge in support of its falsity is that there are many Philonian conditionals that are (they contend) just obviously not true. The following two conditionals (one with a false antecedent and a false consequent, and one with a false antecedent and a true consequent) are fairly typical examples of Philonian conditionals that Anti-Philonians regard as just obviously not true.

If New York is not in the United States, it's in California.

If New York is not in the United States, it's in the United States.

I will call the first of these two conditionals 'the first specimen' and the second 'the second specimen'.

In what follows, I present an argument for the conclusion that the first specimen is true. I consider and reply to several possible criticisms of the argument. I then defend the position that the argument has implications that go beyond the truth-value of one bizarre sentence; I contend that if the argument is sound the Philonian thesis is true.

I am grateful to John Hawthorne, Daniel Nolan, Frank Jackson, and audiences at Notre Dame and Oxford for important criticisms of earlier versions of this essay and for valuable suggestions about how it might be improved.

${ }^{\text {I }}$ After Philo of Megara, the first defender-or the first history records—of the position that a conditional is false if and only if its antecedent is true and its consequent false. 
And, finally, I briefly mention the most important arguments for the falsity of the Philonian thesis.

The argument I give for the truth of the first specimen will perhaps bring the rule of inference

$$
p \vee q \vdash \text { if } \sim p \text {, then } q
$$

- generally known as the 'or-to-if inference'-to the reader's mind. ${ }^{2}$ Nevertheless, the argument does not in any clear sense contain an application of, nor does it in any clear sense depend on the validity of, the or-to-if inference. (For one thing, neither the word 'or' nor the symbol ' $\mathrm{V}$ ' occurs in the argument.) The argument could be regarded as an argument for, or at least an argument that lends support to, the validity of the or-to-if inference. But I shall not in this essay consider the question of the validity of the or-to-if inference.

And here is the argument. (I will refer to it in the sequel as 'the 'first argument'.)

Imagine that Elizabeth Warren has said, 'New York is in the United States', and that I have said, 'New York is in California'. ${ }^{3}$ Then the following argument (in the narrow, numbered-premises-and-conclusion sense of 'argument') is sound. And its conclusion-the first specimen-is therefore true.

I. If New York is not in the United States, then what Senator Warren said was not true

Premise

2. At least one of us — the senator and I-said something true

Premise

3. If what Senator Warren said was not true, and if at least one of us said something true, then what I said was true

Premise

4. If New York is not in the United States, then what I said was true

5. If what I said was true, New York is in California

I, 2, 3

Premise

6. If New York is not in the United States, it's in California.

\section{4, 5}

\footnotetext{
${ }^{2}$ The designation 'the or-to-if inference' is due to Jonathan Bennett (2003: see particularly sections 9 and I 8). As Bennett says, 'The or-to-if inference haunts the literature on indicative conditionals' (2003: 44).

${ }^{3}$ That New York is in the United States is something the senator might well have said. From a US State Department news briefing: 'Well, the United Nations is located in New York. New York is in the United States. It's our view, as host nation, that we should. . $\therefore$. As to my statement-that New York is in California-you might imagine that it was some sort of joke or figure of speech (perhaps in aid of the thesis that the whole of the United States has become like California). If anyone should protest that Senator Warren and I have not actually said these things and that the argument is therefore unsound, I ask that person to consider instead the following argument. Imagine a possible world W in which (a) terrestrial geography is the same as it is in the actual world, and (b) Warren and I have said these things. If the argument presented in the text is valid, it is sound in $\mathrm{W}$ and the first specimen is true in $\mathrm{W}$. And if the first specimen is true in W, it will be true in the actual world-owing to the fact that if the first specimen is true in a world $w$, it will be true in any world in which terrestrial geography is the same as it is in $w$.
} 
2.

An Anti-Philonian interlocutor (the Interlocutor) speaks:

But that argument is not sound, for it is not valid. It is not valid because it employs the following two rules of inference, neither of which is valid

If $p$, then $q ; r$; if $q \& r$, then $s \vdash$ if $p$, then $s$

If $p$, then $q$; if $q$, then $r \vdash$ if $p$, then $r$.

It is obvious that if the latter rule is invalid, the former is as well. I will therefore examine only the latter. I call this rule 'hypothetical syllogism for indicative conditionals'. There are well-known counterexamples to the validity of hypothetical syllogism for indicative conditionals. Suppose, for example, that I don't know the outcome of yesterday's race, but I believe that two horses, Onslaught and Bishop's Gaiters, were far stronger runners than any of the other entrants, and that one of the two-I have no idea which-won and the other came in second. I thus believe that

7. If Onslaught didn't win, he finished in second place. ${ }^{4}$

And, of course, I also believe that

8. If Onslaught didn't run, he didn't win,

owing to the fact that that sentence is analytic or logically true (or whatever your preferred term is for sentences like 'If someone is a bachelor, he is unmarried' and 'If two people are of different ages, one of them is older than the other'). But, if hypothetical syllogism for indicative conditionals is valid, then

9. If Onslaught didn't run, he finished in second place

is a formal logical consequence of (7) and (8) (compare Burgess (2009: 80 ). Moreover, in whatever sense 'Onslaught didn't win' is an informal logical consequence of 'Onslaught didn't run', (9) is an informal logical consequence of $(7)$ if hypothetical syllogism for indicative conditionals is valid. And it would be absurd to suppose that 'If Onslaught didn't run, he finished in second place' is any sort of logical consequence of 'If Onslaught didn't win, he finished in second place'. Therefore, to accept hypothetical syllogism for indicative conditionals is to accept a rule of inference whose validity would have absurd consequences.

\footnotetext{
${ }^{4}$ Did the Interlocutor just employ the or-to-if inference? You may well ask. But I will not press the point because (7) seems plausible enough (given that the two horses in question are indeed far stronger runners than any other horse in the race) for it simply to be accepted on its own merits: there is really no need to justify it by deducing it from something else.
} 
$3 \cdot$

Well, Interlocutor, fair enough. I would, however, make several points in response. (Response, not protest: I did say, 'fair enough'. Their purpose is only to make clear my own reaction to the Interlocutor's objection to hypothetical syllogism for indicative conditionals.) I am sorry to have to tell you that there are six of them.

(i)

There seems to me to be no sentence such that, if it were substituted for ' $q$ ' in 'If New York is not in the United States, then $q$ ' and 'If $q$, then New York is in California', the result would be two obviously true conditionals. If there indeed is no such sentence, that seems to me to imply that, whether hypothetical syllogism for indicative conditionals is a valid rule of inference or not, one cannot plausibly charge that an argument whose conclusion is 'If New York is not in the United States, it's in California' begs the question because it employs hypothetical syllogism for indicative conditionals. (I confess, however, to being unable to provide a satisfactory account of the idea of begging the question.)

Even those who dispute the validity of hypothetical syllogism for indicative conditionals should grant that there is a strong prima facie case for the validity of that venerable inference-form-owing to the fact that philosophers and mathematicians have been confidently applying it for millennia. ${ }^{5}$ (Suppose the following argument-formally identical with the first argument-occurs in a school geometry textbook:

We have proved the following two statements:

I. If $A B$ equals $B C$, then $A B C D$ is a square

2. EFGH is congruent with $\mathrm{ABCD}$.

It is obvious that

3. If $\mathrm{ABCD}$ is a square and $\mathrm{EFGH}$ is congruent with $\mathrm{ABCD}$, then $\mathrm{EFGH}$ is a square.

And from (I), (2) and (3) it follows that

4. If $\mathrm{AB}$ equals $\mathrm{BC}$, then $\mathrm{EFGH}$ is a square.

It is also obvious that

5. If $\mathrm{EFGH}$ is a square, then $\mathrm{EF}$ equals $\mathrm{GH}$.

\footnotetext{
${ }^{5}$ I myself employed hypothetical syllogism for indicative conditionals in note 3. (Albeit the conclusion of the argument-'If the argument in the text is valid, the first specimen is true in the actual world' was left unstated.) I wonder: Did any anti-Philonian reader of this essay object to the argument of note 3 on that ground?
} 
And it follows from (4) and (5) that

6. If $\mathrm{AB}$ equals $\mathrm{BC}$, then $\mathrm{EF}$ equals $\mathrm{GH}$.

Who will be so bold as to charge its author with fallacious reasoning?)

Not only has hypothetical syllogism for indicative conditionals been confidently employed for millennia, but writers on philosophical logic have been confidently asserting its validity for millennia. According to Alexander of Aphrodisias (third century A.D.), Aristotle's student Theophrastus (possibly reproducing material from late, unpublished writings of his teacher) listed

If $\mathrm{A}$ then $\mathrm{B}$; if $\mathrm{B}$ then $\Gamma$; therefore, if $\mathrm{A}$ then $\Gamma$

as the simplest hypothetical syllogism (all hypothetical syllogisms were held to be valid; the more complicated ones are generated by negating various of the schematic letters). Alexander's example of an instance of this schematic inference was, 'If a man exists, an animal exists; if an animal exists, a substance exists; therefore, if a man exists, a substance exists'. ${ }^{6}$ (See Kneale and Kneale I962: I Io.) At the other end of those millennia (or near enough), we find in Strawson's Introduction to Logical Theory the statement that that the 'law'

'if $p$, then $q$; and if $q$, then $r$ ' entails 'if $p$, then $r$ '

'holds good' - that is, that this is not one of the many cases in which a 'law' that holds for ' $\supset$ ' fails when 'if-then' is substituted for 'כ ' (I952: 87-88).

I regard the Interlocutor's contention that ' $(9)$ is an informal logical consequence of (7)' is absurd as the result of a mistaken inference from the fact that (7) is assertible and (9) is not. (I do not suppose that anyone will maintain that that all the logical consequences of assertible statements are assertible.) I regard (9) as precisely analogous to 'If Mars has three moons, then the number of Martian moons is even': both are what might be called modally counterintuitive Philonian conditionals. (For any sentences $p$ and $q$, $\ulcorner$ If $p$, then $q\urcorner$ is a modally counterintuitive Philonian conditional just in the case that $p$ is false and $\ulcorner$ If $p$, then $\sim q\urcorner$ is a necessary truth.) For it is evident that 'Onslaught either won or finished in second place' implies 'Onslaught ran' and thus implies that (9) is a Philonian conditional. And we Philonians have long since made our peace with the fact that the Philonian thesis implies that modally counterintuitive Philonian conditionalsbeing, as they are, Philonian conditionals-are true. (Note that the second specimen is a modally counterintuitive Philonian conditional.)

\footnotetext{
${ }^{6}$ Compare Aristotle, Prior Analytics, i. 32 (47 $\left.{ }^{\mathrm{a}} 28\right)$.
} 
$(\mathbf{v})$

There is, of course, the question of the other rule the Interlocutor has mentioned, the rule needed to justify the inference of line 4 of the first argument from lines I, 2, and 3 . We might call it 'strong hypothetical syllogism for indicative conditionals'. I am simply going to assume that strong hypothetical syllogism for indicative conditionals is valid if hypothetical syllogism for indicative conditionals is. An eminently doubtful assumption, you may tell me, since it is hard to see how strong hypothetical syllogism for indicative conditionals could be valid unless hypothetical syllogism for indicative conditionals and 'consequent strengthening' - that is

$$
\text { If } p \text {, then } q ; r \vdash \text { if } p \text {, then } q \& r-
$$

were $b o t h$ valid. And the validity of consequent strengthening would confer validity on arguments like 'If Tom is in his study, he's working on his paper on the A-series; Tom is asleep in his bedroom; hence, if Tom is in his study, he's working on his paper on the A-series and he's asleep in his bedroom'.

In my view, however, that argument is valid, and its oddness is due to the fact that its two premises are not jointly assertible or jointly entertainable. They are, however, as one might say, severally assertible and entertainable. Suppose that they are severally entertained: Tom's colleague Miriam, who knows a lot about Tom's current philosophical projects and his work habits, believes that if Tom is in his study, he's working on his paper about the A-series; but Tom's wife June knows something Miriam doesn't know, to wit that a few minutes ago Tom decided that his work on the A-series would go better if he came back to it after a little nap, and that he's now asleep in their bedroom. It is easy to imagine that a philosopher might wish to advance some thesis that made reference to the logical consequences of the union of the set of beliefs of one person and the set of beliefs of another person. I am perfectly comfortable with saying that 'If Tom is in his study, he's working on his paper on the A-series and he's asleep in his bedroom' is a logical consequence of the conjunction of Miriam's belief that if Tom is in his study, he's working on his paper on the A-series, and June's belief that Tom is asleep in their bedroom.

The validity of both hypothetical syllogism for indicative conditionals and strong hypothetical syllogism for indicative conditionals is easily demonstrated using the method of conditional proof for indicative conditionals - that is, the principle

For any sentences $p, q$, and $r$, if $r$ can be validly deduced from $p$ and $q$, then $\ulcorner$ If $q$, then $r\urcorner$ can be validly deduced from $p$.

\section{4 .}

I have no responses to (ii)-(v) to put into the Interlocutor's mouth, since I am not sure how the Anti-Philonians (whom that creature of fiction stands in for) would respond to them. (They will probably not dispute (i).) I am, however, quite sure how they 
would respond to (vi). I am sure that they would respond by rejecting the method of conditional proof for indicative conditionals. I would expect them to say something like this:

You can't expect us Anti-Philonians to agree that conditional proof for indicative conditionals is a valid method of proof. (We do of course accept the obviously true principle 'For any sentences $p$ and $q$, if $q$ can be validly deduced from $p$, then $\ulcorner$ If $p$, then $q\urcorner$ can be validly deduced from the empty premise-set'-conditional proof for indicative conditionals without premises, one might call it.) For it's easy to show that the validity of conditional proof for indicative conditionals has the following consequence: if addition $(p \vdash p \vee q)$ and disjunctive syllogism $(p \vee q ; \sim p \vdash q)$ are valid rules of inference, then any conditional can be validly deduced from the denial of its antecedent.

All right. Point taken. Again, fair enough. I would nevertheless point out that there is a lot to be said for conditional proof for indicative conditionals. We do seem to employ it in our everyday reasoning about conditionals. Consider for example, this exchange:

Alex: If every member of the committee voted, the vote wasn't a tie

Belinda: How so?

Alex: Well, the number of committee members is odd. You can have a tie vote only if the number of people voting is even. So, if all the members voted, the vote wasn't a tie.

I think it is fair to say that if one were to make Alex's reasoning fully explicit, it would look something like this:

The number of committee members is odd

The vote was a tie only if the number of people who voted was even

If every member of the committee voted and the number of committee members is odd, then the number of people who voted is odd

If the number of people who voted is odd, it is not even

bence [since 'The vote wasn't a tie' can be validly deduced from 'Every member of the committee voted' and those four statements],

If every member of the committee voted, the vote wasn't a tie.

It seems evident to me that Alex's reasoning is valid. The simplest explanation of its validity is that conditional proof for indicative conditionals is a valid method of proof. (I do not mean this observation to amount to anything more than a consideration that favors conditional proof for indicative conditionals-for the simplest explanation is not always the right explanation. Perhaps there are 
possible applications of conditional proof for indicative conditionals that lack some feature that is present in Alex's reasoning and are invalid because they lack that feature. I cannot see what that 'feature' might be, but, much as I should like to believe that my failure to see such a feature proves that no such feature exists, I have to concede that it doesn't prove that.)

\section{$5 \cdot$}

In any case, whether conditional proof for indicative conditionals is a valid method of proof or not, I have given an argument for the truth of the first specimen whose only disputable feature is its employment of the inference-rules hypothetical syllogism for indicative conditionals and strong hypothetical syllogism for indicative conditionals. It therefore seems to me to be a good argument-an argument that is about as good as it is possible for a philosophical argument for a positive ${ }^{7}$ and controversial conclusion to be.

Now let us generalize this result. For any conditional with a false antecedent, there are arguments for its truth that proceed from the assumption that some given person has asserted its consequent and that some given person has asserted the denial of its antecedent-arguments that are sound if and only if the first argument is sound. This fact amounts to an argument for the conclusion that all conditionals with false antecedents are true-an argument that is about as good as it is possible for a philosophical argument for a positive and controversial conclusion to be. It is not a knock-down argument, I grant you, it is not a proof-it is not that good. But, as David Lewis has said, 'The reader in search of knockdown arguments in favor of my theories will go away disappointed. Whether or not it would be nice to knock disagreeing philosophers down by sheer force of argument, it cannot be done. Philosophical theories are never refuted conclusively. (Or hardly ever. Gödel and Gettier may have done it.)' (Lewis I983: $\mathrm{x}$ ).

6.

We have, from the previous section,

Io. For any conditional with a false antecedent, there are arguments for the truth of that conditional that are sound if and only if the first argument is sound.

Now let us consider a small modification of the first argument, a modification that produces the second argument. Imagine that Elizabeth Warren has said, 'New York is in the United States,' and that Angus King has also said, 'New York is in the United States.' Then the following argument (in the narrow, numbered-premisesand-conclusion sense of 'argument') is sound. And its conclusion-the second specimen-is therefore true.

${ }^{7}$ For an explanation of the qualification positive, reflect for a moment on the allusions to certain achievements of Gödel and Gettier in the quotation from Lewis that follows in the text. 
[Place here the result of replacing 'I' with 'Angus King' (with appropriate changes of grammatical person) and 'New York is in California' with 'New York is in the United States' in sentences (I)-(6) above.]

Two further things are evident:

II. For any conditional with a true consequent, there are arguments for the truth of that conditional that are sound if and only if the second argument is sound.

I2. The second argument is sound if and only if the first argument is sound.

It follows from (IO), (I I), and ( I 2) that if the first argument is sound, all Philonian conditionals are true. But all conditionals that are not Philonian conditionals are false-since they are the conditionals with true antecedents and false consequents. And, therefore, if the first argument is sound, a conditional is true if and only if it is a Philonian conditional.

\section{$7 \cdot$}

I have said nothing about the arguments against the Philonian thesis (other than arguments based on the supposedly intuitively obvious falsity of certain Philonian conditionals). The most important of these arguments fall into three categories.

One of these categories comprises arguments of this form:

If the Philonian thesis is true, the rule of inference $R$ is valid. And there are counterexamples to the validity of $R$.

Two such ' $R$ 's are hypothetical syllogism and consequent strengthening-typical (alleged) counterexamples to which we have considered. Four others are: (i) antecedent strengthening (if $p$, then $q ; r \vdash$ if $p \& r$, then $q$ ); (ii) contraposition (if $p$, then $q \vdash$ if $\sim q$, then $\sim p$ ); (iii) disjunctive antecedent simplification (if $p \vee q$, then $r \vdash$ if $p$, then $r$ ); and (iv) conjunctive antecedent simplification (if $p \& q$, then $r \vdash$ if $p$, then if $q$, then $r$ ).

The arguments in another of the categories concern the consequences of asserting the falsity of (or affirming the denials of) conditionals. For example:

Suppose Hildegard is taking a true-false test, and that she marks 'Labour will not win the next election' ' $T$ ' and marks 'If Labour win the next election, the National Health Service will be abolished' 'F.' If the Philonian thesis is true, Hildegard has thereby contradicted herself. And she obviously has not. ${ }^{8}$

A pious youth says to Bertrand Russell, 'It's a pretty risky business being an atheist like you. I mean, if God exists, you'll go to hell'. Russell replies, 'Young man, that is simply not true. If God exists, then when I die he'll say to me, 'Well done, my son. You have apportioned your belief to the

${ }^{8}$ Compare Edgington I99I: I8I-82. 
evidence available to you. Enter into the Kingdom of Heaven.' And you, young man, you he'll send straight to hell!' If the Philonian thesis is true, then 'God exists' follows from Russell's statement that the pious youth's conditional statement ('If God exists, you'll go to hell') was 'simply not true.' And it is obvious that it does not follow.

(We might assimilate this category to the previous category, the ' $R$ ' in this case being ' $\sim$ (if $p$, then $q$ ) $\vdash p$ '-but arguments like these two bulk large in the literature, large enough, I think, to merit a category of their own.)

The arguments in the remaining category concern supposed violations of the obviously true principle that if $p$ entails $q$, the probability of $p$ is less than or equal to the probability of $q$ (and the probability of $p$ on $r$ is less than or equal to the probability of $q$ on $r$ ). I give two examples (the second of which is directed not at the Philonian thesis itself, but at the validity of the first argument. ${ }^{9}$ ):

If the Philonian thesis is true, 'Labour will not win the next election' entails 'If Labour win the next election, the National Health Service will be abolished'. But if $p$ entails $q$, the probability of $q$ is greater than or equal to the probability of $p$. And, obviously, the probability of 'If Labour win the next election, the National Health Service will be abolished' is far lower than the probability of 'Labour will not win the next election'. The Philonian thesis is therefore false. ${ }^{\text {Io }}$

The first argument is invalid. For consider an argument that is like the first argument, but in which the role played by 'New York is in the United states' is played by a proposition whose denial is not vastly improbable. Let us suppose that Kamala Harris has said, 'Joe Biden is in Wilmington,' and that I have said, 'Joe Biden is on the moon.' Suppose Biden is indeed, as Harris said, in Wilmington. It cannot be that

If Biden is not in Wilmington, he's on the moon

follows from the four statements

If Biden is not in Wilmington, then what Harris said was not true

At least one of us-Harris and I-said something true

If what Harris said was not true, and if at least one of us said something true, then what I said was true

If what I said was true, Biden is on the moon.

\footnotetext{
${ }^{9}$ I have chosen not to examine this objection to the first argument in this essay because it will be convenient to examine all the arguments that concern the application of the principle 'If $p$ entails $q$, the probability of $p$ (on $r$ ) is less than or equal to the probability of $q$ (on $r$ )' to questions about conditionals in one place. And that place is not this place.

${ }^{\text {IO }}$ Compare Edgington 20I4: section 2.3 ('Arguments against Truth-Functionality’).
} 
For (conditional on the truth of the 'set-up story') the probability of the proposition that all four premises are true is I-for the set-up story (as a set-up story should) entails those premises. But the probability of 'If Biden is not in Wilmington, he's on the moon' (conditional on . . .) is as close to $\circ$ as makes no matter. But if $q$ follows from $p$, then the probability of $q$ on $r$ must be greater than or equal to the probability of $p$ on $r$. Therefore, the conclusion of the parallel argument does not follow from its premises. ${ }^{\text {II }}$

What must be done, if the truth of the Philonian thesis is to be further investigated, is to compare the force of these arguments with the force of the arguments for the truth of the Philonian thesis-including the argument I have presented. This I will attempt on another occasion.

PETER VAN INWAGEN

THE UNIVERSITY OF NOTRE DAME vaninwagen.I@nd.edu

\section{References}

Bennett, Jonathan. (2003) A Philosophical Guide to Conditionals. Oxford: Oxford University Press. Burgess, John P. (2009) Philosophical Logic. Princeton: Princeton University Press.

Edgington, Dorothy. (I99I) 'Do Conditionals Have Truth-Conditions?' In Frank Jackson (ed.), Conditionals (Oxford: Oxford University Press), I76-20I.

Edgington, Dorothy. (20I4) 'Indicative Conditionals'. In Edward N. Zalta (ed.), The Stanford Encyclopedia of Philosophy. https:/plato.stanford.edu/archives/win2or 4/entries/conditionals/.

Kneale, William, and Martha Kneale. (1962) The Development of Logic. Oxford: Clarendon Press. Lewis, David. (1983) Philosophical Papers. Vol. I. New York: Oxford University Press Strawson, P. F. (1952) An Introduction to Logical Theory. London: Methuen.

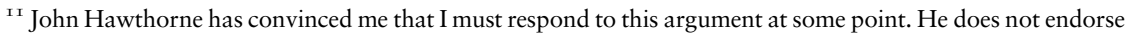
the argument but does maintain that at the very least it constitutes an important objection to my argument for the Philonian thesis.
} 